\title{
HIGHER RISK OF COMPLICATIONS AFTER TOTAL KNEE ARTHROPLASTY IN OCTOGENARIANS
}

\section{OCTOGENÁRIOS APRESENTAM MAIOR RISCO DE COMPLICAÇÕES APÓS ARTTOPLASTIA TOTAL DO JOELHO}

\author{
Gabriel Garcez de Araujo Souza ${ }^{1}$ (i), Raphael Soejima Correia Ramalho ${ }^{1}$ (i), Rodrigo Sattamini Pires e albuquerque ${ }^{1,2}$ (i),

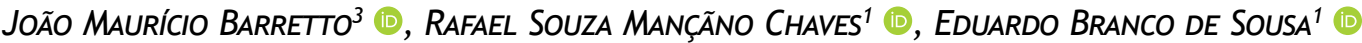

1. Instituto Nacional de Traumatologia e Ortopedia, Knee Surgery Center, Rio de Janeiro, RJ, Brazil.

2. Universidade Federal Fluminense, Niterói, RJ, Brazil.

3. Clínica São Vicente, Rio de Janeiro, RJ, Brazil.

\section{ABSTRACT}

Objective: To evaluate the complication rate of total knee arthroplasty (TKA) in octogenarian patients and identify predictive factors. Methods: The study comprised 70 octogenarians and 70 non-octogenarian patients as control group, all submitted to TKA. We analyzed the medical records of these patients, seeking for complications during the first postoperative year. Regarding the risk factors, we evaluated: age, sex, race, American Society of Anesthesiologists score, body mass index, smoking, hypertension and diabetes mellitus. Results: In the control group, the incidence of complications was $7.1 \%$. Whereas in the octogenarian group it was significantly higher, reaching 34.3\% (OR 6.8; 95\% Cl 2.4-19.1). We found no association to sex, skin color, and comorbidities. Age is an independent risk factor for postoperative complications. Our data may help patients to acknowledge the risks of undergoing primary TKA and physicians to assess and adjust perioperative risk. Conclusion: The incidence of postoperative complications is significantly higher in octogenarians. Level of Evidence III, Case-control study.

Keywords: Arthroplasty. Knee. Postoperative Complications. Aged, 80 and over.

\section{RESUMO}

Objetivo: O objetivo do estudo foi avaliar a taxa de complicações da artroplastia total do joelho (ATJ) em pacientes octogenários e tentar identificar fatores preditivos. Métodos: Foi realizado um estudo envolvendo 140 pacientes, divididos em dois grupos (70 octogenários e 70 com idade abaixo de 80 anos), submetidos a ATJ no período de janeiro de 2014 a agosto de 2016. Os prontuários desses pacientes foram analisados buscando a presença de complicações ocorridas no prazo de um ano após a cirurgia. Em relação aos fatores de risco foram avaliados idade, sexo, raça, American Society of Anesthesiologists, Indice de Massa Corpórea, tabagismo, hipertensão arterial e diabetes. Resultados: No grupo-controle, a incidência de complicações foi de 7,1\%. Já no grupo estudado foi significativamente maior, chegando a 34,3\%. A razão de chances para complicações é 6,8, com intervalo de confiança ao nível de 95\% igual a $(2,4 ; 19,1)$. A idade maior ou igual a 80 constitui, assim, fator de risco aumentado para a incidência de complicações pós-artroplastia total de joelho. Conclusão: A ocorrência de complicações após ATJ é significativamente maior no grupo dos octogenários. Nível de Evidência III, Estudo de caso-controle.

Descritores: Artroplastia. Joelho. Complicações Pós-Operatórias. Idoso de 80 Anos ou Mais.

Citation: Souza GGA, Ramalho RSC, Albuquerque RSP, Barreto JM, Chaves RSM, Sousa EB. Higher risk of complications after total knee arthroplasty in octogenarians. Acta Ortop Bras. 2020;28(4):177-81. Available from URL: http://www.scielo.br/aob.

\section{INTRODUCTION}

Total knee arthroplasty (TKA) is a high-complexity orthopedic procedure indicated for treating patients with severe knee osteoarthritis to relieve pain, improve joint function and correct deformities to improve patients' quality of life.'

The age up from which a person is considered old varies, but there is a consensus around 64 years. In 1963, the World Health
Organization recommended the following categorical definition: middle age, 45 to 59 years; active seniors, 60 to 74 years; dependent seniors, 75 to 90 years; and oldest-old, over 90 years. $^{2}$

Because of the increase in life expectancy and medical progress, elderly patients have been progressively submitted to more complex, longer and larger surgical interventions. ${ }^{2}$

Age is a non-modifiable risk factor. Aging alters the natural history of diseases: it is considered a risk factor for various diseases and

All authors declare no potential conflict of interest related to this article.

The study was conducted at Instituto Nacional de Traumatologia e Ortopedia, Knee Surgery Center

Correspondence: Gabriel Garcez de Araujo Souza. Rua Santa Clara, 50, sala 421, Rio de Janeiro, RJ, Brazil, 22041012. drgabrielgarcez@genutarso.com.br 
a determinant for longer hospital stay and higher incidence of adverse drug reactions. ${ }^{2}$

The American Society of Anesthesiology (ASA) score has changed little over the years. It remains one of the most used for its practicality and sensitivity in predicting patients' overall risk of mortality based on age and functional status, regardless of the type of procedure that will be performed. ${ }^{3}$

Despite total knee arthroplasty being successful, 11 to $20.8 \%$ of patients develop perioperative complications, ${ }^{4,5}$ among which the most common are: surgical wound, thromboembolic disease, infection, neurovascular lesions, periprosthetic fracture, extensor mechanism injury, and joint stiffness. ${ }^{4}$ Surgery complications in elderly patients will be focused due to aging; that is, due to their lower adaptability to environmental changes and to their own homeostasis as a result of organic reserve reduction. ${ }^{2}$

This study aimed to evaluate the complications of total knee arthroplasty in octogenarian patients and identify predictive factors.

\section{MATERIALS AND METHODS}

A cross-sectional (observational) study was performed involving patients over 60 years old with primary osteoarthritis of the knee and submitted to total arthroplasty with cement between January 2014 and August 2016.

The study included patients who underwent TKA with one-year follow-up: the study group consisted of 70 octogenarian patients, and the control group consisted of 70 patients between 60 and 65 years. All patients had clinical indication for primary TKA and formed a homogeneous group with moderate osteoarthritis of the knee (Ahlback II/III) and no severe deformities (varus/valgus: 15 degrees). The same surgical protocol was applied to all patients during the procedure, as follows. The surgery was performed with spinal anesthesia associated with combined femoral and sciatic nerve block. Arthroplasty was performed under ischemia with pneumatic tourniquet inflated to $125 \mathrm{mmHg}$ above patient's systolic pressure after limb exsanguination. The procedures were performed with classic medial parapatellar approach and patients in supine position. In all cases, Hemovac ${ }^{\circledR}$ drains were placed and removed within 24 postoperative, with corresponding output. Posterior-stabilized Press-Fit Condylar (PFC sigma/DePuy-Synthes ${ }^{\circledR}$ ) Sigma implants with patellar replacement were used. The pneumatic tourniquet was released before wound closure. Surgeons members of our Hospital knee group (all members of the Sociedade Brasileira de Cirurgia do Joelho) performed the surgeries. Antimicrobial surgical prophylaxis protocol (Cefazolin/24 hours) was applied to all patients, as well as for thromboembolic events (low-molecular-weight heparin for 15 days), as effective norms of the institution.

The standard postoperative rehabilitation protocol was applied for both groups, without distinctions. Motion and gait training were stimulated during the first or second postoperative day.

Data were collected by the analysis of patients' medical records. We evaluated the incidence of postoperative complications during the first postoperative year for both groups and also the risk factors for complications following TKA, such as: age, sex, race, American Society of Anesthesiology (ASA) score, body mass index (BMI), history of smoking, and presence of hypertension and Diabetes Mellitus. We considered complications any events that modified normal postoperative evolution, requiring any kind of intervention or acceptance of functional loss by the patient.

The complications or outcomes observed in the medical records were categorized into systemic and local. The frequency of outcomes was analyzed from the intraoperative period until the end of the first postoperative year. Systemic complications were subdivided into: pulmonary - pulmonary embolism; cardiac - acute myocardial infarction, and others. Local complication was subdivided into acute arterial occlusion, deep vein thrombosis, skin necrosis, superficial or deep surgical site infection, amputation, and others.

This study was approved by the Research Ethics Committee of our institution (CAAE: 79996217.9.0000.5273) and followed the National Health Council recommendations for Research Involving Human Beings.

The data were tabulated in Microsoft Excell ${ }^{\circledR}$ for analysis. Descriptive statistics characterized the variable Age of the study population by: frequencies; proportions; minimum, maximum and mean values; standard deviations, median, and coefficient of variation (CV). The variability of distribution of age was classified following the convention: low variability, if $\mathrm{CV}<0.20$; moderate, if $0.20 \leq \mathrm{CV}<0.40$; and high, if $\geq 0.40$.

For inferential analysis, the Binomial test compared two complementary proportions. The chi-square was used to investigate the significant association between two qualitative variables; whenever its results were inconclusive and the situation was appropriate (tables $2 \times 2$ ), Fisher's exact test was used. Odds Ratio was used to express risk, which evaluated the chance of an individual in a group presenting a complication outcome in relation to the chance of an individual in the complementary group presenting a complication outcome. The OR significance level was assessed by the OR confidence interval, which cannot contain the value 1 , as it would mean individuals from different groups present the same chance for the analyzed outcome. Kolmogorov-Smirnov test (KS) and the Shapiro-Wilk test (SW) verified the hypothesis of normality of distribution of age. Distribution was considered normal if both tests did not reject the null hypothesis of normality. As normality of the distribution of age was rejected for both groups, the Mann-Whitney test compared patients' ages from two independent groups.

Statistical analyses were performed by 20.0 Statistical Package for the Social Sciences ${ }^{\circledR}$ (SPSS), and graphics were built in Microsoft Excel $2007^{\circledR}$. Discussions regarding the tests were conducted considering a $5.0 \%$ maximum significance level.

\section{RESULTS}

Our research sample was composed by 140 patients with primary osteoarthritis of the knee submitted to total arthroplasty with cement: 107 female (76.4\%) and 33 male (23.6\%), as shown in Figure 1.

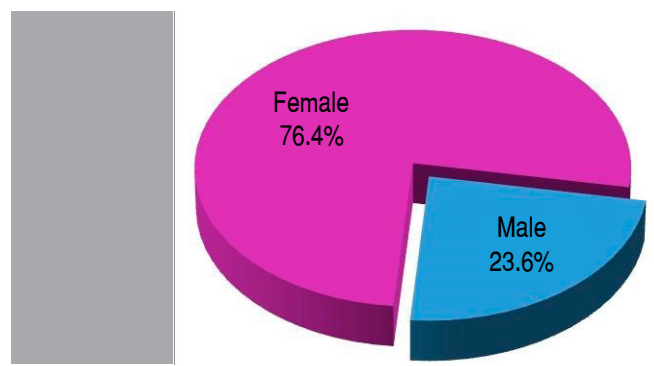

Figure 1. Distribution of patients by sex.

Table 1 describes the main analyses of the age distribution of patients, overall and by sex. Overall, patients were between 60 and 94 years old, mean and median of 73.0 years, and standard deviation of 10.3 years with coefficient of variation of 0.149 , denoting low variability between patients' ages. From the $p$ values for the normality tests, we concluded that age did not follow normal distribution, neither in the overall sample nor in female and male groups. Thus, the Mann-Whitney test compared distributions of age within female and male patients, resulting in $p=0.115$. We found no significant difference between the distributions of age in male and female patients. 
Table 1. Key statistics of patients' age, overall and by sex.

\begin{tabular}{c|c|c|c}
\hline Statistics & Overall & Female & Male \\
\hline Minimum & 60 & 60 & 60 \\
\hline Maximum & 94 & 94 & 90 \\
\hline Mean & 73.0 & 74.1 & 69.5 \\
\hline Standard deviation & 10.3 & 10.3 & 9.8 \\
\hline Median & 73 & 80 & 64 \\
\hline CV & 0.14 & 0.14 & 0.14 \\
\hline KS test $p$ value & 0.000 & 0.000 & 0.000 \\
\hline SW test $p$ value & 0.000 & 0.000 & 0.000 \\
\hline
\end{tabular}

The group of patients over 80 years old, herein "Octogenarian Group," comprises $50 \%$ of the sample. Table 2 shows the frequency distribution of variables that characterize patients in octogenarian and non-octogenarian groups. The proportion of male patients in the octogenarian group (14.3\%) is significantly lower than that in the non-octogenarian group (32.9\%), chi-square test. $p=0.010$. White and mixed-race were predominant among patients, and we found no significant difference among the distribution of skin color in both groups $(p=0.054)$. All patients had an ASA score equal to two. Within our study sample, the most prevalent comorbidities were: $\mathrm{SAH}$, affecting $85.0 \%$ of patients; Diabetes Mellitus, with $17.1 \%$ prevalence; and obesity, with $12.1 \%$ prevalence. According to the $p$-values of the association tests, only the prevalence of obesity was significantly different between both groups: the proportion of obese patients in the octogenarian group (4.3\%) was significantly lower than in the non-octogenarian group (20.0\%), $p=0.004$. We found no significant difference in the prevalence of other comorbidities between both groups.

Table 2. Patients' characteristics, overall and within interest groups.

\begin{tabular}{|c|c|c|c|c|c|c|c|}
\hline \multirow[t]{2}{*}{ Characteristic } & \multicolumn{2}{|c|}{ Overall } & \multicolumn{2}{|c|}{$\begin{array}{c}\text { Non- } \\
\text { octogenarians } \\
\end{array}$} & \multicolumn{2}{|c|}{ Octogenarians } & \multirow[t]{2}{*}{$\begin{array}{c}\text { test } \\
p \text {-value }\end{array}$} \\
\hline & $\mathbf{F}$ & $\%$ & $\mathbf{F}$ & $\%$ & $\mathbf{F}$ & $\%$ & \\
\hline \multicolumn{8}{|l|}{ Gender } \\
\hline Female & 107 & $76.4 \%$ & 47 & $67.1 \%$ & 60 & $85.7 \%$ & 0.010 \\
\hline Male & 33 & $23.6 \%$ & 23 & $32.9 \%$ & 10 & $14.3 \%$ & \\
\hline \multicolumn{8}{|l|}{ Skin color } \\
\hline White & 56 & $40.0 \%$ & 21 & $30.0 \%$ & 35 & $50.0 \%$ & 0.054 \\
\hline Mixed race & 65 & $46.4 \%$ & 38 & $54.3 \%$ & 27 & $38.6 \%$ & \\
\hline Black & 19 & $13.6 \%$ & 11 & $15,7 \%$ & 8 & $11.4 \%$ & \\
\hline \multicolumn{8}{|l|}{ Comorbidities } \\
\hline SAH & 119 & $85.0 \%$ & 58 & $82.9 \%$ & 61 & $87.1 \%$ & 0.478 \\
\hline $\mathrm{DM}$ & 24 & $17.1 \%$ & 11 & $15,7 \%$ & 13 & $18.6 \%$ & 0.654 \\
\hline Obesity & 17 & $12.1 \%$ & 14 & $20.0 \%$ & 3 & $4.3 \%$ & 0.004 \\
\hline $\begin{array}{c}\text { Hypo/ } \\
\text { hyperthyroidism }\end{array}$ & 11 & $7.9 \%$ & 3 & $4.3 \%$ & 8 & $11.4 \%$ & 0.116 \\
\hline Depression & 8 & $5.7 \%$ & 4 & $5.7 \%$ & 4 & $5.7 \%$ & $1,000^{(b)}$ \\
\hline Dyslipidemia & 8 & $5.7 \%$ & 2 & $2.9 \%$ & 6 & $8.6 \%$ & $0.275^{(b)}$ \\
\hline Smoking & 7 & $5.0 \%$ & 5 & $7.1 \%$ & 2 & $2.9 \%$ & $0.441^{(b)}$ \\
\hline Prostate & 5 & $3.6 \%$ & 0 & $0.0 \%$ & 5 & $7.1 \%$ & $0.058^{(b)}$ \\
\hline Bronchitis/Asthma & 4 & $2.9 \%$ & 1 & $1.4 \%$ & 3 & $4.3 \%$ & 0.620 \\
\hline Prior CVA & 3 & $2.1 \%$ & 0 & $0.0 \%$ & 3 & $4.3 \%$ & $0.245^{(b)}$ \\
\hline Anemia & 2 & $1.4 \%$ & 1 & $1.4 \%$ & 1 & $1.4 \%$ & $1,000^{(b)}$ \\
\hline $\mathrm{AF}$ & 2 & $1.4 \%$ & 1 & $1.4 \%$ & 1 & $1.4 \%$ & $1,000^{(b)}$ \\
\hline CRF & 2 & $1.4 \%$ & 1 & $1.4 \%$ & 1 & $1.4 \%$ & $1,000^{(b)}$ \\
\hline Epilepsy & 1 & $0.7 \%$ & 0 & $0.0 \%$ & 1 & $1.4 \%$ & $1,000^{(b)}$ \\
\hline Gout & 1 & $0.7 \%$ & 1 & $1.4 \%$ & 0 & $0.0 \%$ & $1,000^{(b)}$ \\
\hline Hepatopathy & 1 & $0.7 \%$ & 0 & $0.0 \%$ & 1 & $1.4 \%$ & $1,000^{(b)}$ \\
\hline Panic Disorder & 1 & $0.7 \%$ & 0 & $0.0 \%$ & 1 & $1.4 \%$ & $1,000^{(b)}$ \\
\hline
\end{tabular}

(b): the chi-square test was inconclusive; therefore, fisher's exact test was performed.
In the overall analysis of the study sample, the incidence of postoperative complications was $20.7 \%$ (39 patients). The chi-square test showed a significant difference in the incidences of complications between both groups $(p=0.000)$. Figure 2 shows the difference between these incidences. In the non-octogenarian group, the incidence of complications was $7.1 \%$ (five patients), whereas in the octogenarian group the incidence of complications was significantly higher (34.3\%; 24 patients). The odds ratio for complications was 6.8 , with $95 \% \mathrm{Cl}$ $(2.4 ; 19.1)$. As the confidence interval of the odds ratio does not contain the value 1 , being 80 years or older represented an increased risk factor for the incidence of complications following total arthroplasty with cement for the treatment of primary osteoarthritis of the knee.

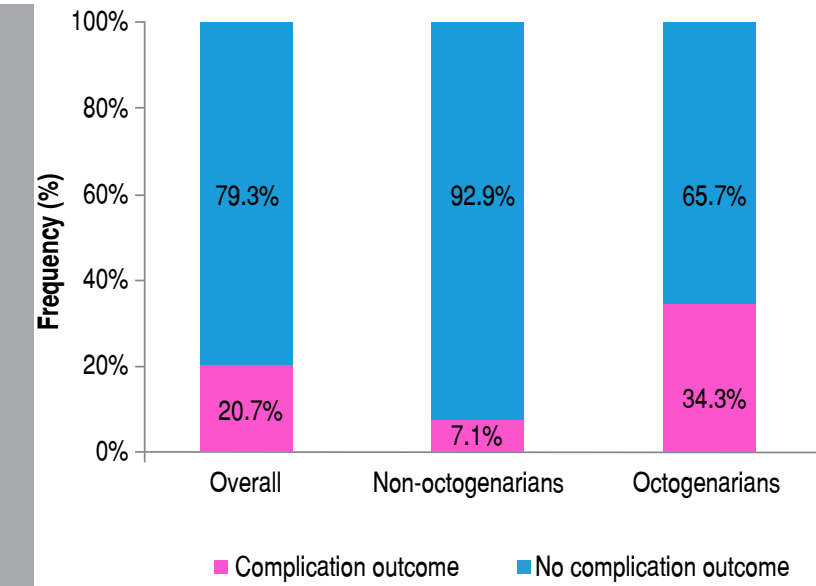

Figure 2. Incidence of complications following total arthroplasty with cement for the treatment of primary osteoarthritis of the knee, overall and within interest groups.

Table 3 shows the description and frequency distribution of postoperative complications of patients submitted to total arthroplasty with cement according to age. Table 3. Frequency distribution of postoperative complications in patients
submitted to total arthroplasty with cement for the treatment of primary
osteoarthritis of the knee, overall and within interest groups.

\begin{tabular}{|c|c|c|c|c|c|c|}
\hline \multirow[t]{2}{*}{ Description of complication } & \multicolumn{2}{|c|}{ Overall } & \multicolumn{2}{|c|}{$\begin{array}{c}\text { Non- } \\
\text { octogenarians } \\
\end{array}$} & \multicolumn{2}{|c|}{ Octogenarians } \\
\hline & $\mathbf{F}$ & $\%$ & $\mathbf{F}$ & $\%$ & $\mathbf{F}$ & $\%$ \\
\hline Loss of range of motion & 5 & 3.5 & 3 & 4.2 & 2 & 2.8 \\
\hline TKA infection & 3 & 2.1 & 2 & 2.9 & 1 & 1.4 \\
\hline Anemia & 2 & 1.4 & 0 & 0 & 2 & 2.8 \\
\hline Cellulitis & 2 & 1.4 & 0 & 0 & 2 & 2.8 \\
\hline Chronic pain & 2 & 1.4 & 0 & 0 & 2 & 2.8 \\
\hline Periprosthetic fracture & 2 & 1.4 & 0 & 0 & 2 & 2.8 \\
\hline Peroneal neuropraxia & 2 & 1.4 & 0 & 0 & 2 & 2.8 \\
\hline Deep vein thrombosis & 2 & 1.4 & 0 & 0 & 2 & 2.8 \\
\hline Anasarca/ IPO Hyponatremia & 1 & 0.7 & 0 & 0 & 1 & 1.4 \\
\hline IPO Decompensated asthma & 1 & 0.7 & 0 & 0 & 1 & 1.4 \\
\hline IPO Pulmonary congestion & 1 & 0.7 & 0 & 0 & 1 & 1.4 \\
\hline Delirium/ IPO ARF & 1 & 0.7 & 0 & 0 & 1 & 1.4 \\
\hline IPO AF & 1 & 0.7 & 0 & 0 & 1 & 1.4 \\
\hline $\begin{array}{l}\text { IPO Hematoma/ } \\
\text { Surgical Dressing } \\
\end{array}$ & 1 & 0.7 & 0 & 0 & 1 & 1.4 \\
\hline $\begin{array}{l}\text { Ligament injury during TKA - } \\
\text { Indicated by TC3 Review }\end{array}$ & 1 & 0.7 & 0 & 0 & 1 & 1.4 \\
\hline Delaying Wound Healing & 1 & 0.7 & 0 & 0 & 1 & 1.4 \\
\hline Intestinal sub-occlusion & 1 & 0.7 & 0 & 0 & 1 & 1.4 \\
\hline
\end{tabular}


The most frequent complication was the loss of the range of motion, affecting $4.2 \%$ of the control group and $2.8 \%$ of the studied group. Infection was the second most prevalent, twice as common in the control group as in the octogenarian group. The two most common complications in both groups were local. Furthermore, some complications occurred solely within the group of octogenarians. Among local complications, we excel cellulitis, chronic pain, periprosthetic fracture, IPO hematoma, ligament injury indicative of surgical revision, delayed wound healing, and peroneal neuropraxia. Among general complications, those that affected solely octogenarian group were anemia, deep vein thrombosis, anasarca, decompensated asthma, pulmonary congestion, delirium, atrial fibrillation, and intestinal sub-occlusion.

\section{DISCUSSION}

TKA is currently the top elective surgery in the United States, ${ }^{6}$ and in patients over 85 years old it represents $5 \%$ of the total. ${ }^{7}$

Fang et al. suggest that octogenarian population presents a lower BMI. ${ }^{8}$ We believe that obesity within this age group represents a factor that increases morbidity or mortality following surgery.

In our culture, the decision for surgery lays with both the patient and his family, regardless of age. Despite the increased risk of complications, patient's careful selection allows a safe surgery with good results. ${ }^{9}$

Van den Belt et al. ${ }^{10}$ found that a high ASA score resulted in a longer hospital stay. However, age was not a factor in increasing the length of stay.

The literature reports high mortality rates during the first 30 postoperative days, as well as high complication and morbidity rates in patients with advanced age. ${ }^{11}$ Thus, the adequate clinical follow-up is one year. Similar researches applied the same evaluation period.12 The literature is controversial regarding the percentage of the complication rates in octogenarians and lacks consistency in defining "complication." Some authors do not consider surgical manipulation as complication. Others consider surgical complications only, excluding clinical complications. ${ }^{7,12}$ Our data collection was thorough, including any event that altered the pattern of a TKA postoperative rehabilitation.

To avoid a selection bias, our study was based on the ASA, and clinical and radiographic patterns of the knee. We believed that large knee deformities and marked bone defects could increase surgical time and bewilder our results.

We found a higher complication rate within the octogenarian group, and several other studies in the literature corroborate our results. ${ }^{13-15}$ However, Seo et al. ${ }^{12}$ observed no differences in complication rates among their study groups.

Kodaira et al.$^{16}$ analyzed complications within octogenarians and the control groups, finding no increase in general clinical complications. In assessing the aseptic implant failure, they reported 5 cases in the younger group and no case in octogenarians. ${ }^{16}$

Kreder et al. ${ }^{15}$ concluded that octogenarians undergoing TKA have a risk of mortality 3.4 times higher than a control group. ${ }^{15}$

Our study reported some general complications restricted to the octogenarian group. Biau et al., ${ }^{17}$ however, found no differences when analyzing the general complications (cardiac, urinary, neuropsychiatric, thromboembolic events, and decubitus ulcers). Fang et al., ${ }^{8}$ that subdivided the sample into five subgroups according to age, observed that complications following TKA increased progressively with aging. Our results are aligned with Tay et al., ${ }^{9}$ which found that aging increases comorbidities and consequently decrease physical capacity. Thus, as an elderly patient has a smaller physiological reserve, surgical aggression is enhanced.

Falls from standing height are the main factor of hospital readmission within the first 90 days. ${ }^{18}$ We had two cases of periprosthetic fracture from falling from standing height during the first postoperative year. The elderly commonly presents loss of muscle mass and bone quality, as well as altered balance, enhancing the risk of fractures. Driesman et al. ${ }^{19}$ showed that joint replacement, whether in the hip or knee, reduces the risk of falls -in the elderly, the major cause of osteoporotic fractures and clinical depreciation. Thus, debating on the risk-benefit of total knee arthroplasty in octogenarians is up-to-date and of collective interest.

Rubin et al. ${ }^{20}$ concluded that no evidence states that elderly patients with comorbidities are associated with increased complications. This literature review article shows that this line of research is open for further studies and that the subject still comprises numerous controversies.

\section{CONCLUSION}

Complications following TKI are age-group related, and their incidence is significantly higher within octogenarians.

AUTHOR'S CONTRIBUTIONS: Each author contributed individually and significantly to the development of this article. GGAS: data collection and drafting of the article; RSCR: data collection and drafting of the article; RSPA: statistical analysis, surgery performance, article organization and final text review; JMB: article review and intellectual concept; RSMC: data collection and project elaboration; EBS: intellectual concept, assistance in project elaboration, and final text review.

\section{REFERENCES}

1. Diduch DR, Insall JN, Scott WN, Scuderi GR, Font-Rodriguez D. Total knee replacement in young, active patients: long-term follow-up and functional outcome. J Bone Joint Surg Am. 1997;79(4):575-82.

2. Gomes M, Ramacciotti E. Profilaxia da doença tromboembólica no paciente idoso. Colégio Brasileiro de Cirurgiões. Programa de Auto-Avaliação em Cirurgia. 2002;(2):2.

3. Leme LEG, Sitta MC, Toledo M, Henriques SS. Cirurgia ortopédica em idosos: aspectos clínicos. Rev Bras Ortop. 2011;46(3):238-46.

4. Morrey BF, Adams RA, Ilstrup DM, Bryan RS. Complications and mortality associated with bilateral or unilateral total knee arthroplasty. J Bone Joint Surg Am. 1987;69(4):484-8.

5. Ayers DC, Dennis DA, Johanson NA, Pellegrini VD Jr. Instructional course lectures, The American Academy of Orthopaedic Surgeons - common complications of total knee arthroplasty. J Bone Joint Surg Am. 1997;79(2):278-311.

6. Pugely AJ, Martin CT, Gao Y, Mendoza-Lattes S, Callaghan JJ. Differences in short-term complications between spinal and general anesthesia for primary total knee arthroplasty. J Bone Joint Surg Am. 2013;95(3):193-9.

7. Kennedy JW, Johnston L, Cochrane L, Boscainos PJ. Total knee arthroplasty in the elderly: does age affect pain, function or complications? Clin Orthop Relat Res. 2013;471(6):1964-9.
8. Fang M, Noiseux N, Linson E, Cram P. The effect of advancing age on total joint replacement outcomes. Geriatr Orthop Surg Rehabil. 2015;6(3):173-9.

9. Tay KS, Cher EWL, Zhang K, Tan SB, Howe TS, Koh JSB. Comorbidities have a greater impact than age alone in the outcomes of octogenarian total knee arthroplasty. J Arthroplasty. 2017;32(11):3373-8.

10. van den Belt $L$, van Essen P, Heesterbeek PJ, Defoort KC. Predictive factors of length of hospital stay after primary total knee arthroplasty. Knee Surg Sports Traumatol Arthrosc. 2015;23(6):1856-62.

11. Parry MC, Smith AJ, Blom AW. Early death following primary total knee arthroplasty. J Bone Joint Surg Am. 2011;93(10):948-53.

12. Seo JG, Moon YW, Cho BC, Kim SC, Ko YH, Jang SP, et al. Is total knee arthroplasty a viable treatment option in octogenarians with advanced osteoarthritis? Knee Surg Relat Res. 2015;27(4):221-7.

13. Stroh DA, Delanois R, Naziri O, Johnson A, Mont M. Total knee arthroplasty in patients over 80 years of age. J Knee Surg. 2011;24(4):279-83.

14. Austin DC, Torchia MT, Moschetti WE, Jevsevar DS, Keeney BJ. Patient outcomes after total knee arthroplasty in patients older than 80 years. J Arthroplasty. 2018;33(11):3465-73.

15. Kreder HJ, Berry GK, McMurtry IA, Halman SI. Arthroplasty in the octogenarian: quantifying the risks. J Arthroplasty. 2005;20(3):289-93. 
16. Kodaira S, Kikuchi T, Hakozaki M, Konno S. Total knee arthroplasty in Japanese patients 80 years or older. Clin Interv Aging. 2019:14:681-8.

17. Biau D, Mullins MM, Judet T, Piriou P. Is anyone too old for a total knee replacement? Clin Orthop Relat Res. 2006;(448):180-4

18. Pitter FT, Jørgensen CC, Lindberg-Larsen M, Kehlet $H$, Lundbeck Foundation Center for Fast-track Hip and Knee Replacement Collaborative Group. Postoperative morbidity and discharge destinations after fast-track hip and knee arthroplasty in patients older than 85 years. Anesth Analg. 2016;122(6):1807-15.
19. Driesman A, Paoli AR, Wiznia DH, Oh C, Mahure SA, Long WJ, et al. Total joint arthroplasty is associated with a decreased risk of traumatic falls: an analysis of 499,094 cases. J Am Acad Orthop Surg [Internet]. 2019 Dec 6 [accessed on 2020 Apr 22]:[about 9 p.]. Available from: https://journals.Iww.com/jaaos/Abstract/9000/Total_Joint_Arthroplasty_Is_Associated With a.99227.aspx.

20. Rubin LE, Blood TD, Defillo-Draiby JC. Total Hip and Knee Arthroplasty in Patients Older Than Age 80 Years. J Am Acad Orthop Surg. 2016;24(10):683-90. 